\title{
A Importância da Equipe Multiprofissional para a recuperação da criança com fenda labiopalatina
}

\author{
Importance of the Multiprofessional Team for the recovery \\ of children with cleft lip and palate
}

Carla Alves de Andrade' $\bullet$ Mylena Costa Rodrigues ${ }^{2} \cdot$ Walquiria Lene dos Santos $^{3}$

\section{RESUMO}

Introdução: Relato de caso de uma criança que nasceu com fenda labiopalatal. Uma alteração que atinge cerca de I a cada 800 crianças, podendo ocorrer por diversos fatores incluindo fatores genéticos e o uso de álcool e drogas feito pela mãe durante o período gestacional. Objetivo: Descrever a trajetória de uma criança que nasceu no Distrito Federal com a má formação no lábio e palato, tendo grande parte do seu tratamento realizado no Hospital Regional da Asa Norte. Este estudo mostra as dificuldades encontradas pela criança portadora da malformação, os cuidados necessários no pré e pós-operatório, na realização das cirurgias e os problemas futuros relatados pelos pais da criança. Método: $O$ estudo trata-se de um relato de caso qualitativo e para obter as informações foram utilizados exames, fotos, entrevistas feitas com o pai e a mãe da criança e uma revisão de literatura como forma de complemento. Resultado: $\mathrm{O}$ caso relatado mostra que quanto antes a criança for submetida aos cuidados necessários, melhor será o resultado final dos tratamentos, evitando assim, que essa condição possa causar transtornos maiores para a vida da paciente conforme for crescendo. Conclusão: $O$ trabalho realizado pela equipe multiprofissional em conjunto com a família da criança, são fundamentais para a superação de dificuldades.

Descritores: Criança; Malformação; Lábio Leporino; Palato

\begin{abstract}
Introduction: Case report of a child born with cleft lip and palate.A change that affects about I in every 800 children, and may occur due to several factors including genetic factors and the mother's use of alcohol and drugs during pregnancy. Objective:To describe the trajectory of a child born in the Federal District with malformation in the lip and palate, and much of his treatment was performed at the Asa Norte Regional Hospital.This study shows the difficulties encountered by the child with the malformation, the necessary pre and postoperative care in performing surgeries and the future problems reported by the child's parents. Method:The study is a qualitative case report and to obtain the information were used exams, photos, interviews with the child's father and mother and a literature review as a complement. Result: The reported case shows that the sooner the child is subjected to the necessary care, the better will be the final outcome of the treatments, thus avoiding that this condition may cause major disruption to the patient's life as she grows up. Conclusion:The work performed by the multiprofessional team together with the child's family are fundamental for overcoming difficulties.
\end{abstract}

Keywords: Kid; Malformation; Cleft Lip; Palate 


\section{INTRODUÇÃO}

A fissura lábio palatina (FLP) é uma malformação congênita, decorrente da falta de fusão do palato durante o período intrauterino, sendo incluída entre uma das anomalias mais comuns. As fissuras labiopalatinas são identificadas pela presença de uma fenda na região óssea ou mucosa da abóbada palatina, podendo ser parcial ou total.'

Os primeiros relatos de fissura labial foram descritas no século I da Era Cristã. Ao longo dos tempos, houve várias tentativas de descrever a etiologia deste tipo de má-formação, porém o real progresso dos procedimentos terapêuticos acontecerão de fato nos últimos 50 anos. ${ }^{2}$

O indivíduo portador da sequela decorrente de fissura labiopalatina pode consequentemente apresentar alterações de diversas naturezas como na comunicação verbal, que se divide nas áreas da fala, voz, linguagem e fluência, podendo acarretar também problemas auditivos. $O$ protocolo de tratamento mais utilizado atualmente é o fechamento do lábio de forma cirúrgica com 3 meses de idade ou quando atinge o peso ideal para realização do procedimento. Já o do palato, é feito em tempo único, com I ano de idade. ${ }^{3}$

O enxerto ósseo alveolar é realizado entre 7 e 9 anos de idade, quando o dente canino está próximo a sua irrupção. $A$ cirurgia ortognática é realizada entre 13 e 15 anos de idade. A cirurgia final do paciente fissurado é a rinoplastia secundária, para correção da deformidade nasal residual. Um protocolo de tratamento bem estabelecido pode levar a índices de sucesso em torno de $96 \%$ na reabilitação dos pacientes fissurados, e depende basicamente de três pilares: I-Adesão do paciente ao tratamento;2- Gravidade da fissura labiopalatina;3- Experiência da equipe multidisciplinar. ${ }^{4}$

Para a completa reabilitação das pessoas com FLP, é necessária uma abordagem interdisciplinar, envolvendo a medicina, a odontologia, a fonoaudiologia, a psicologia, a enfermagem, fisioterapia e o serviço social. $A$ atenção à saúde nessa área atinge todos os níveis de complexidade, e as intervenções para o enfrentamento desse problema, em diversos países, são realizadas em centros especializados e hospitais públicos e privados. No Brasil a principal referência para a realização dessas cirurgias de forma gratuita é o Hospital de Reabilitação de Anomalias Craniofaciais da Universidade de São Paulo - HRAC/USP - Centrinho, de Bauru, que através do Sistema Único de Saúde (SUS) realizam as correções sem nenhum custo financeiro para a família dos portadores de qualquer malformação que afete a face. ${ }^{5}$

Com isso o presente trabalho tem por objetivo descrever a trajetória de uma criança que nasceu no Distrito Federal com a má formação no lábio e palato. Este estudo mostra as dificuldades encontradas pela criança portadora da malformação, os cuidados necessários no pré e pós-operatório, na realização das cirurgias e os problemas futuros relatados pelos pais da criança.

\section{MÉTODOS}

Trata-se de um relato de caso, método de descrição detalhada, onde é feito uma anamnese dos entrevistados abordando pontos importantes sobre determinado caso, trazendo informações que já aconteceram e que estão vivendo atualmente. ${ }^{6}$ Abordando uma criança que nasceu no Distrito Federal com fissura lábiopalatina (Lábio + Palato) e que ao longo de seu crescimento foi submetida a diversos procedimentos, a maioria deles no Hospital Regional da Asa Norte-HRAN, para sua reabilitação e melhora na qualidade de vida.

A pesquisa foi realizada através do acesso a fichas, registros fotográficos comparativo de antes e depois dos procedimentos, exames da paciente e entrevista semi-estruturada com os pais da criança na cidade de Valparaíso de Goiás a qual reside atualmente. Foram incluídos como auxílio na pesquisa, artigos em inglês e em português que abordaram de forma clara o assunto, e foram excluídos artigos que não se tratavam apenas de Lábio Leporino e Fenda Palatina, ou seja, aqueles que incluíam outra patologia associada a essa malformação.

A coleta de dados foi realizada por meio de entrevista feita com os pais, que abordou desde a descoberta da malformação, a realização das cirurgias de correção, o pré e pós-operatório até as alterações apresentadas pela paciente no decorrer do seu crescimento, realizando entrevistas mensais durante 0 ano de $2018 \mathrm{com}$ duração em média de 30 minutos à uma hora, sendo feitas no período da tarde, no qual a criança se encontrava na escola. Esses encontros foram realizados na casa de seus responsáveis, onde tudo que relataram foi gravado no celular em forma de áudio. Os pontos analisados como mais importantes foram também anotados em um caderno separado apenas para isso.

Foi executada também uma revisão das fichas e exames da criança, apresentados pelos pais e todo relato foi concluído com a autorização dos responsáveis, assim como o conteúdo disponibilizado por eles e anexado no seguinte estudo. $O$ trabalho foi submetido e aprovado pelo Comitê de Ética e Pesquisa - CEP com o número I7|61019.3.0000.5595.

\section{Relato de caso}

Os pais relatam ter tomado conhecimento da malformação da criança durante um exame de rotina do pré-natal, na ultrassonografia morfológica feita durante $\bigcirc$ quinto mês de gestação. A partir daí tomaram conhecimento sobre o problema e começaram a receber as informações necessárias através da equipe de apoio do posto de saúde no qual fazia o acompanhamento da gravidez.A mãe relatou possuir familiares que já nasceram com esse tipo de malformação.

Paciente M.C.S.A. nasceu no dia $1 \mathrm{I} / \mathrm{II} / 20 \mathrm{I}$ com 38 semanas, de parto normal, no Hospital Regional do Gama - HRG teve icterícia e necessitou ficar na incubadora para tratamento eletrofototerapêutico. Durante sua estadia no hospital se alimentava através de leite oferecido no copinho, pois não conseguia se alimentar através do peito da mãe.Após 5 dias internadas no hospital a mãe e a criança foram para casa e começaram as consultas da paciente.

Os pais optaram por realizar o tratamento da filha em Brasília no HRAN por ser de fácil acesso a eles e por terem encontrado confiança na equipe de profissionais que fizeram seu atendimento.As consultas foram realizadas com frequência, toda segunda-feira e foram diminuindo conforme a criança crescia até se tornarem mensais. $E$ às vezes, a criança chegava a passar por diversos profissionais como cirurgiões, pediatra, nutricionistas em um mesmo dia e sempre sendo auxiliados pela enfermeira chefe do local.

O procedimento cirúrgico de fechamento da fenda labial é simples, dura cerca de duas horas, e é necessário que a criança esteja sob anestesia geral. Durante as cirurgias de fendas labiopalatais, além da anestesia geral é feito a intubação orotraqueal. Usa-se de preferência o tubo aramado devido à sua flexibilidade e menor possibilidade de colabamento. Sendo posicionado na linha média da boca, sem desvios das 
comissuras labiais ou da língua. Associadamente, o cirurgião infiltra solução de lidocaína 0,5\% com adrenalina a I/200.000, no lábio, e a I//00.000, no palato.Após autorização do anestesista, o paciente é colocado em posição supina, com o pescoço em hiperextensão e a mesa em Trendelenburg. Para auxiliar no posicionamento do corpo é colocado um coxim sob os ombros. Não devera ser feito nenhum movimento brusco sem o conhecimento do anestesista, visto que, na maioria dos casos, trata-se de pacientes de tenra idade nos quais são utilizados tubos orotraqueais que não possuem balonete. $A$ extubação acidental pode ocorrer facilmente e deve ser evitada. $A$ antisepsia é feita com clorexidina degermante e em seguida clorexidina alcoólica, na face, e com clorexidina degermante, na cavidade oral. Toda face do paciente fica exposta, inclusive nas palatoplastias. Já as pálpebras devem ser mantidas em oclusão com o auxílio de fitas adesivas ${ }^{7}$.

Após a cirurgia a paciente é encaminhada para sala de pósanestesia, onde aguarda aproximadamente uma hora e meia, até que acorde e se recupere, para então ser encaminhada ao quarto.

A primeira cirurgia da criança aconteceu com 6 meses de idade, como mostra a figura I (antes da cirurgia ) e a figura 2 (após a cirurgia), pois antes disso ela não tinha o peso necessário para a realização do procedimento.A internação no hospital foi de apenas 3 dias, a mãe deu entrada com a criança no primeiro dia no período da tarde, ficou em um quarto onde se encontravam outras crianças que também realizariam procedimentos parecidos, pela mesma equipe médica. Era necessário manter a criança em jejum por 8 horas, para a realização da cirurgia que estava agendada para o segundo dia pela manhã. Nessa primeira etapa foi feito a realização do fechamento apenas do lábio. A alta se deu no terceiro dia pela manhã.

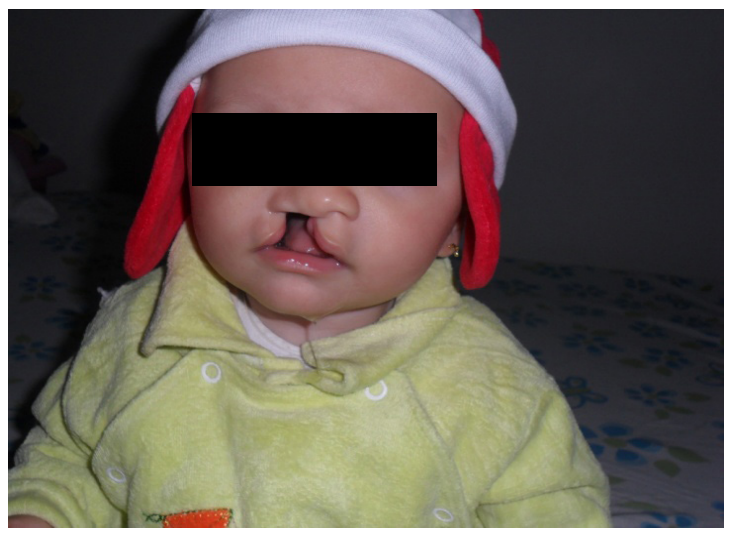

Figura I - Foto feita antes da realização do primeiro procedimento cirúrgico, com 6 meses de idade.

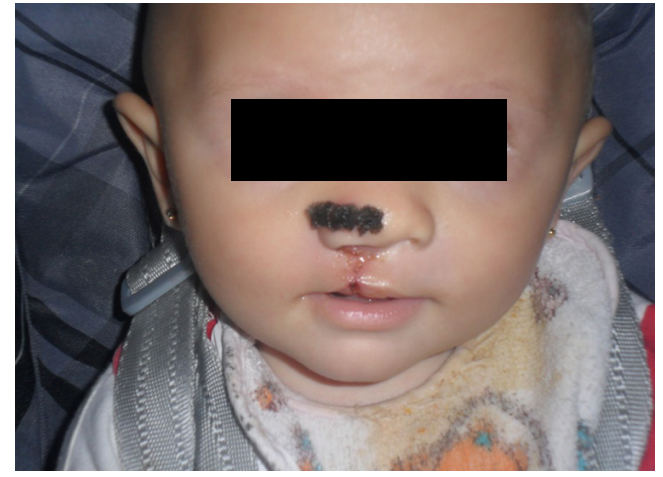

Figura 2 - Algumas semanas após a realização da cirurgia de correção do lábio leporino.
Os pais relatam esse ser um dos momentos mais complicados passado pela criança, pois ela não podia usar mamadeira na qual era acostumada e a alimentação tinha que ser diferenciada, não podendo ingerir alimentos sólidos nem quentes, seguindo uma dieta líquida, processada e fria, evoluindo para uma dieta pastosa e morna. Por volta de um mês, houve uma rápida cicatrização e sua recuperação estava dentro do esperado, podendo retornar a alimentação normal. ${ }^{8}$

A segunda cirurgia foi feita com um intervalo de aproximadamente 6 meses da primeira, segundo o pai da criança. Foi realizada a correção do fechamento parcial do palato (como mostra a figura 3) e a internação ocorreu da mesma forma que a primeira, ficando no hospital por apenas 3 dias, levando a mudanças na alimentação da criança, sendo necessário seguir todas as orientações médicas para que a recuperação fosse total.

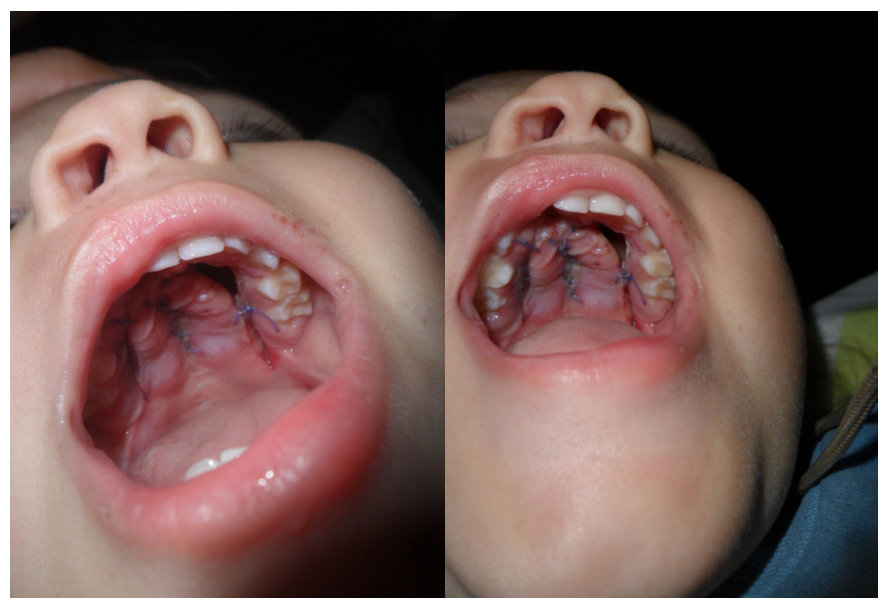

Figura 3 - Alguns dias após a cirurgia de fenda palatina (segunda cirurgia realizada).

A terceira e última cirurgia realizada no HRAN foi feita para concluir o fechamento total do palato e aconteceu antes da criança completar 2 anos de idade. Desde então os acompanhamentos com a fonoaudióloga foram realizadas de forma mais frequente, enquanto as outras consultas diminuíam. Após isso, a criança apresentou um desenvolvimento normal.

No final do ano de 2017 os pais notaram uma alteração na audição da criança e exames foram realizados, suas noites de sono eram agitadas apresentando também quadros frequentes de infecção de ouvido e garganta. $\bigcirc$ resultado da audiometria apontou uma perda parcial de audição nos dois ouvidos devido a uma infecção decorrente da má formação dos ossos face. De início o médico optou por realizar o tratamento com antibióticos para cessar a infecção, o tratamento funcionou a curto prazo, pois logo o problema voltou, foi então que os pais começaram a fazer o acompanhamento de forma mais frequente com um médico otorrinolaringologista da rede particular, pois a demora entre uma consulta e outra no HRAN estava aumentando, devido a grande demanda de crianças para serem atendidas.

Em 2018 novos exames foram realizados em períodos diferentes, e foi apontada a necessidade de uma nova cirurgia, dessa vez o cirurgião era o médico otorrinolaringologista que já estava acompanhando a criança por mais de um ano e que além da perda de audição se preocupou também com os problemas secundários que ela estava apresentando, como o sono agitado e as infecções frequentes de garganta. 
O médico solicitou a realização de vários procedimentos de uma vez, a cirurgia do ouvido (timpanotomia para tubo de ventilação), do nariz (turbinoplastia), a retirada das amigdalas (amigdalectomia das platinas), e de adenoide (adenoidectomia por videoendoscopia). Procedimentos simples, mas que feitos de uma só vez, evitariam que a criança precisasse se submeter a outro procedimento cirúrgico novamente no futuro.

No começo de novembro de 2018 aconteceu a realização das cirurgias citadas, no Hospital Daher, através do plano de saúde do pai. A cirurgia ocorreu dentro de 3 horas e meia e a criança passou a noite no hospital com os pais, sendo liberada no dia seguinte.Após duas semanas de recuperação e mudança na alimentação e nas suas atividades diárias, a criança já estava recuperada. A audição melhorou, pois ela já não assistia televisão com o som alto, não sendo mais necessário que os pais falassem em tom de voz maior para que ela os ouvisse, melhorando assim, até seu desenvolvimento em sala de aula e suas noites de sono se tornaram tranquilas.

No começo do ano de 2019 a criança já com 7 anos de idade começou o tratamento ortodôntico mais intenso novamente no HRAN. Foi preciso passar por uma mini cirurgia para extração de um dos dentes que havia nascido torto na fenda da gengiva, um procedimento simples, com anestesia local necessitando apenas de um ponto no local da extração. Depois de algumas radiografias dos dentes foi possível observar uma má oclusão esquelética na sua face, necessitando assim da utilização de um aparelho ortodôntico para terapia denominada tração reversa de maxila, que até o momento está apontada para dar início no segundo semestre de 2019.

A previsão é para que novas cirurgias e novos procedimentos aconteçam tanto ortodônticos quanto estéticos, que deverão ser realizados no HRAN segundo os pais da criança e se espera que a última cirurgia seja feita quando a paciente atingir a maior idade, sendo uma cirurgia estética fornecida pelo SUS no qual a paciente fará a correção da assimetria do rosto conforme desejada.

A FLP é um problema simples dentre as demais patologias e deformidades existentes nos dias de hoje, porém o tratamento é feito ao longo da vida, desde seu nascimento até a idade adulta dos pacientes portadores de FLP, sendo sempre acompanhados pelos seus médicos, que juntamente com os pais buscam oferecer a eles o mais importante que é a sua qualidade de vida. 9

\section{DISCUSSÃO}

A incidência no Brasil de nascidos vivos com lábio leporino, podendo ser associada ou não à fissura palatina é cerca de uma em cada 800 crianças. ${ }^{9}$ A cada 2 minutos, uma criança nasce com algum tipo de fissura facial no mundo, sendo elas labial, no palato ou outras deformidades recorrentes de fatores genéticos ou ambientais como o uso de álcool, cigarros, drogas ou medicamentos ingeridos pela mãe durante o período gestacional. $^{10}$

O SUS é essencial em todo processo de atendimento aos portadores de LFP, disponibilizando o tratamento sem custo benefício para esses pacientes. Oferece todo tratamento cirúrgico e acompanhamento necessário dos diversos profissionais da saúde. E foi aprovado em 2019 de acordo com o projeto de lei (PL) II72/15 se tornando obrigatório esse atendimento mais ampliado e melhor através do SUS.Visto que os adultos que não possuem esse tipo de tratamento sofrem com diversos transtornos como baixa autoestima, bullying, diminuição da sua qualidade de vida, problemas de saúde constante, entre outros fatores. "

Os problemas secundários causados por essa deformidade podem gerar grandes transtornos para o paciente incluindo o preconceito. Para que isso seja evitado e a reabilitação seja satisfatória se faz necessário o envolvimento de uma equipe multidisciplinar para $\circ$ atendimento dessas pessoas, desenvolvendo um papel de grande importância nessa trajetória, que pode se estender por anos. Apesar de não diminuir a expectativa de vida, a fissura lábio palatina compromete alterações de grande relevância em aspectos funcionais, estéticos e até mesmo sociais, por isso se faz necessário o atendimento de uma equipe qualificada. ${ }^{12}$

O trabalho do profissional de fisioterapia com a criança portadora de FLP pode acontecer de duas maneiras, uma delas é a melhora na função respiratória desses pacientes, visto que a malformação causa toda uma mudança na estrutura óssea podendo levar a dificuldades respiratórias, sendo então necessária a intervenção do fisioterapeuta. $E$ as crianças que além da FLP possuem outro tipo de problema associado, como Síndrome de Down o fisioterapeuta entra com técnicas posturais e motoras para um melhor prognóstico desses pacientes. $^{12,13}$

Já o enfermeiro, participa desde a avaliação inicial, verificando sinais vitais, no pré-operatório, no qual explica a mãe da criança sobre a amamentação, que pode sim ocorrer através dos seios, sendo sempre com o lactante sentado, para não correr risco de aspiração. Durante a cirurgia, é ele quem acompanha de forma contínua, esclarece sobre todos os riscos e sana dúvidas. No pós-operatório, por exemplo, é ele o responsável pela limpeza da sutura, antes de sua remoção e por ensinar os cuidados, após tirá-la. E ele é quem faz o agendamento das consultas, passa as orientações, acompanhando a criança e sua família em todas as etapas nesse processo de reabilitação. ${ }^{12,13}$

É fundamental que os portadores dessa malformação sejam encaminhados para uma avaliação e consequentemente ao tratamento adequado logo nos primeiros dias de vida, para isso, é necessário que os pais do paciente recebam as orientações adequadas logo após a descoberta, pois quanto antes for o atendimento melhor serão as chances de evitar maiores danos. ${ }^{13}$

$\mathrm{Na}$ fase de recuperação dos portadores de fissura lábiopalatina, a atenção do enfermeiro nesse processo é indispensável, pois além de oferecer o suporte necessário entre uma operação e outra, será ele quem passará as informações aos familiares para com a paciente, dentre as diversas complicações em várias atividades diárias, bem como a alimentação e cuidados necessários a serem tomados devido aos procedimentos realizados. Esse trabalho sendo realizado em conjunto pelos profissionais da saúde e os familiares do paciente é o que vai garantir uma vida normal, sem maiores problemas no futuro. ${ }^{13}$

\section{CONCLUSÃO}

O caso relatado mostra que o tratamento precoce de uma criança portadora de FLP obtém resultados satisfatórios para o paciente e que os profissionais trabalhando juntamente com os pais durante esse processo podem ter resultados ainda melhores. O SUS oferece tratamentos gratuitos em diversos estados do Brasil no qual poucas pessoas têm conhecimento desse tratamento. Com isso, esperamos que a elaboração do presente estudo ajude a ampliar melhor os conhecimentos 
sobre malformações faciais em especial as que apresentam lábio leporino e fenda palatina, a fim de contribuir de forma positiva para a sociedade.

\section{REFERÊNCIAS}

1. Freitas JS, Cardoso MCAF. Sintomas de disfagia em crianças com fissura labial e/ou palatina pré e póscorreção cirúrgica. CoDAS. 2017; 30(I):I-7.

2. Almeida AMFL, Chaves SCL, Santos CML, Santana SF. Atenção à pessoa com fissura labiopalatina:proposta de modelização para avaliação de centros especializados, no Brasil. Revista Saúde Debate. 20I7; 4I(I):I56-I66.

3. Miachon MD, Leme PLS. Tratamento operatório das fendas labiais. Rev. Col. Bras. Cir. 20I4; 4I(3):208215.

4. Fernandes R, Defani MA. Importância da equipe multidisciplinar no tratamento e preservação de fissuras labiopalatinas. Rev Saúde e Pesquisa. 2013; 6(1):109-116.

5. Bachega MI. Fissura Labiopalatina. Hospital de Reabilitação de Anomalias Craniofaciais Universidade de São Paulo. [Internet]. Copyright. 2018; [acesso em 23 de Dezembro de 2018]. Disponível em: http://hrac. usp.br/saude/fissura-labiopalatina/.

6. Yoshida WB. Redação do relato de caso. J Vasc Bras. 2007; 6(2): II2-II3.

7. Franco D, Eyler AD. Cirurgia de Fissurados: Detalhes que Facilitam. Rev. Soc. Bras. Cir. Plast. 2003; I8(I):5569.

8. Trettene AS, Mondini CCSD, Marques IL. Alimentação da criança no pós-operatório imediato de palatoplastia: comparação entre as técnicas utilizando copo e colher. Rev Esc Enferm USP. 20 I3; 47(6): I 298-I 304.

9. Barbieri KC.Assistência da enfermagem em portadores de fissura lábio palatina. Cuiabá: Universidade de Cuiabá, 2018. Trabalho de Conclusão de Curso em Enfermagem.

10. Sousa MLB. Orientações da equipe multidisciplinar para os pais de crianças com lábio leporino e/ou fenda palatina: proposta de uma tecnologia educativa. Belém: Fundação Santa de Misericórdia do Pará, 2016.

11. Haje L. CCJ aprova tratamento obrigatório para lábio leporino no SUS [Internet]. Câmara dos deputados. [acesso em 20 Maio 2019]. Disponível em: https:// www2.camara.leg.br/camaranoticias/noticias/ SAUDE/574560-CCJ-APROVA-TRATAMENTOOBRIGATORIO-PARA-LABIO-LEPORINO-NO-SUS. html.

12. Antunes VL, Arruda KA, Conti TGT de, Lopes IMB, Silveira JSZ, Silva TMS. Fisioterapia respiratória em pacientes com fissuras labiopalatinas: rotinas do Hospital de Reabilitação de Anomalias Craniofaciais. Anais. 2013.

13. Fundação para reabilitação das deformidades craniofaciais.Fissura labiopalatal [Internet].2019.[acesso em 19 Junho 2019]. Disponível em: http://www.fundef. org.br/pagina.php?cont=especialidadesFissura.

Recebido: 2019-07-01

Aceite: $2019-10-16$ 